\title{
ON TWO BIVARIATE ELLIPTIC MEANS
}

\section{EDWARD NEUMAN}

Abstract. This paper deals with the inequalities involving the Schwab-Borchardt mean $S B$ and a new mean $N$ introduced recently by this author. In particular optimal bounds, for $S B$ are obtained. Inequalities involving quotients $N / S B$, for the data satisfying certain monotonicity conditions, are derived.

Mathematics subject classification (2010): 26E60, $26 \mathrm{D} 05$.

Keywords and phrases: Schwab-Borchardt mean, the $N$-mean, inequalities, optimal bounds, quotients of bivariate means.

\section{REFERENCES}

[1] G. D. Anderson, M. K. Vamanamurthy, M. Vuorinen, Monotonicity rules in calculus, Amer. Math. Monthly 133 (2006), no. 9, 805-816.

[2] J. M. Borwein, P. B. Borwein, Pi and the AGM - A Study in Analytic Number Theory and Computational Complexity, Wiley, New York, 1987.

[3] B. C. CARlson, Algorithms involving arithmetic and geometric means, Amer. Math. Monthly 78 (1971), 496-505.

[4] S.-B. Chen, Z.-Y. He, Y.-M. ChU, Y.-Q. Song, X.-J. TAO, Note on certain inequalities for Neuman means, J. Inequal. Appl. 2014 2014:370, 10 pages.

[5] Z.-J. Guo, Y.-M. Chu, Y.-Q. Song, X.-J. TAO, Sharp bounds for Neuman means by harmonic, arithmetic, and contra-harmonic means, Abstr. Appl. Anal. Volume 2014, Article ID914242, 8 pages.

[6] Z.-J. Guo, Y. Zhang, Y.-M. Chu, Y.-Q. Song, Sharp bounds for Neuman means in terms of geometric, arithmetic and quadratic means, J. Math. Inequal 10 (2016), no. 2, 301-312.

[7] Y.-M. Li, B.-Y. Long, Y.-M. CHU, Sharp bounds for the Neuman-Sándor mean in terms of generalized logarithmic mean, J. Math. Inequal. 4 (2012), no. 4, 567-577.

[8] E. NEUMAN, Inequalities for the Schwab-Borchardt mean and their applications, J. Math. Inequal. 5 (2011), no. 4, 601-609.

[9] E. NEUMAN, Refinements and generalizations of certain inequalities involving trigonometric and hyperbolic functions, Adv. Inequal. Appl. 1 (2012), no. 1, 1-11.

[10] E. Neuman, A note on a certain bivariate mean, J. Math. Inequal. 6 (2012), no. 4, 637-643.

[11] E. Neuman, Sharp inequalities involving Neuman-Sándor and logarithmic means, J. Math. Inequal. 7 (2013), no. 3, 413-419.

[12] E. Neuman, A one-parameter family of bivariate mean, J. Math. Inequal. 7 (2013), no. 3, 399-412.

[13] E. Neuman, On some means derived from the Schwab-Borchardt mean, J. Math. Inequal. 8 (2014), no. 1, 171-183.

[14] E. NEUMAN, On some means derived from the Schwab-Borchardt mean II, J. Math. Inequal. 8 (2014), no. 2, 359-368.

[15] E. Neuman, On a new bivariate mean, Aequat. Math. 88 (2014), no. 4, 277-289.

[16] E. Neuman, On a new bivariate mean II, Aequat. Math. 89 (2015), 1031-1040.

[17] E. NEUMAN, Inequalities and bounds for a certain bivariate elliptic mean, will be submitted to J. Math. Inequal.

[18] E. Neuman, J. SÁndor, On the Schwab-Borchardt mean, Math. Pannon. 14 (2003), no. 2, $253-266$.

[19] E. Neuman, J. SÁndor, On the Schwab-Borchardt mean II, Math. Pannon. 17 (2006), no. 1, 49-59.

[20] E. NEumAn, J. SÁndor, Inequalities for the ratios of certain bivariate means, J. Math. Inequal. 2 (2008), no. 3, 383-396. 
[21] E. NeUmAn, J. SÁNDOR, On some inequalities involving trigonometric and hyperbolic functions with emphasis on the Cusa-Huygens, Wilker and Huygens inequalities, Math. Inequal. Appl. 13 (2010), no. $4,715-723$.

[22] W.-M. QIAn, Y.-M. ChU, Refinements and bounds for Neuman means in terms of arithmetic and contra-harmonic means, J. Math. Inequal. 9 (2015), no. 3, 873-881.

[23] W.-M. QIAN, Z.-H. ShaO, Y.-M. ChU, Sharp inequalities involving Neuman means of the second kind and other bivariate means, J. Math. Inequal. 9 (2015), no. 2, 531-540.

[24] H.-J. SeIFFERT, Problem 887, Nieuw. Arch. Wisk. 11 (1993), 176.

[25] H.-J. SEIFFERT, Aufgabe 16, Würzel 29 (1995), 87.

[26] F. W. J. Olver, D. W. Lozier, R. F. Boisvert, C. W. Clark, eds., The NIST Handbook of Mathematical Functions, Cambridge Univ. Press, New York, 2010.

[27] Y. Zhang, Y.-M. CHU, Y.-L. JiAng, Sharp geometric mean bounds for Neuman mean, Abstr. Appl. Anal., Volume 2014, Article ID 949815, 6 pages.

[28] T.-H. ZhaO, Y.-M. CHU, B.-Y. LiU, Optimal bounds for Neuman-Sándor mean in terms of arithmetic and contra-harmonic means, Abstr. Appl. Anal., Volume 2012, Article ID 302635, 9 pages. 